\title{
Early childhood internalizing problems, externalizing problems and their co-occurrence and (mal)adaptive functioning in emerging adulthood: a 16-year follow-up study
}

\author{
İldeniz B. Arslan ${ }^{1}$ (1) Nicole Lucassen ${ }^{1} \cdot$ Pol A. C. van Lier ${ }^{1,2} \cdot$ Amaranta D. de Haan $^{1} \cdot$ Peter Prinzie $^{1}$
}

Received: 8 November 2019 / Accepted: 1 September 2020 / Published online: 22 September 2020

(c) The Author(s) 2020

\begin{abstract}
Purpose A vast amount of studies suggest that internalizing or externalizing problems are related to individual functioning, and often co-occur. Yet, a focus on their additive and interactive effects is scarce. Furthermore, most research has focused on a limited number of developmental domains and mostly on maladaptive functioning. Therefore, the current prospective study examined whether early childhood (ages 4-8) internalizing and externalizing problems and their interaction were related to a broad range of (mal)adaptive functioning outcomes in emerging adulthood (ages 20-24).

Methods Data from the Flemish Study on Parenting, Personality and Development were used. At Time 1 (1999) mothers of 374 children ( $45 \%$ boys) and fathers of 357 children ( $46 \%$ boys) rated internalizing and externalizing problems through the Child Behavior Checklist. Outcomes in emerging adulthood were measured through self-reports 16 years later across the following domains: psychological functioning, social functioning, work, physical health, and self-concept.

Results Early externalizing problems were related to maladaptive outcomes on the psychological and social domains. With regard to adaptive functioning, externalizing problems were associated with lower satisfaction regarding general health on the physical domain. Early internalizing problems were not associated with any emerging adulthood outcomes. The interaction of (father reported) internalizing and externalizing problems was related to aggressive behavior.

Conclusion Early childhood externalizing problems were associated with maladaptive and adaptive functioning over a time span of 16 years. The results add to studies on the implementation of prevention and intervention programs in early childhood and to the value for developing personalized interventions.
\end{abstract}

Keywords Early childhood $\cdot$ Internalizing and externalizing problems $\cdot$ Co-occurrence $\cdot$ (Mal)Adaptive functioning · Emerging adulthood

Electronic supplementary material The online version of this article (https://doi.org/10.1007/s00127-020-01959-w) contains supplementary material, which is available to authorized users.

İldeniz B. Arslan

arslan@essb.eur.nl

1 Department of Psychology, Education and Child Studies, Erasmus University Rotterdam, Burgemeester Oudlaan 50, 3000 Rotterdam, The Netherlands

2 Department of Clinical, Neuro and Developmental Psychology, VU University Amsterdam, De Boelelaan 1105, 1081 Amsterdam, The Netherlands

\section{Introduction}

"Give me a child until he is seven and I will show you the man" might be one of the best-known quotes of Aristotle, underpinning the theoretical importance and influence of early childhood on long-term outcomes. A vast amount of studies suggest that internalizing and externalizing problems have concurrent and longitudinal effects on individual functioning (e.g., [1-3]) and often co-occur (e.g., [4]). However, these studies face limitations with regard to the generalizability of their findings as a focus on additive and interactive effects of internalizing and externalizing problems in population samples is scarce. Also, as most studies focused on maladaptive societal functioning outcomes, relatively less is known about general functioning in emerging adulthood, in maladaptive and adaptive terms. Furthermore, studies on 
early childhood functioning are commonly based on single informants. This study adds to current knowledge by examining the extent to which additive and interactive effects of early childhood internalizing and externalizing problems, rated by mothers and replicated by father reports, are related to maladaptive and adaptive general functioning in emerging adulthood.

\section{Early childhood internalizing and externalizing problems}

Externalizing problems entail aggressive and oppositional behavior, whereas internalizing problems consist of anxious and depressed symptoms, withdrawn behavior, and somatic symptoms [5]. Externalizing problems predict a variety of functioning outcomes, such as delinquency throughout adolescence [6], social problems from middle childhood to emerging adulthood [1] and poor academic achievement from middle childhood to early adolescence [7]. Internalizing problems have received relatively less attention. Yet, studies have pointed out that internalizing problems can have negative consequences as well. For example, Goodwin and colleagues [8] reported that childhood internalizing problems were associated with anxiety and depression in adolescence and emerging adulthood. Although often studied as two separate domains, internalizing and externalizing problems often co-occur (e.g., [9]). Co-occurring problems are present in childhood, adolescence, and adulthood. However, the onset of co-occurrence is most often found in early childhood $[4,10]$. This emphasizes the importance of studying additive and interactive associations of early childhood internalizing and externalizing problems, particularly in terms of a better understanding of their long-term prospective associations with developmental outcomes [11]. Remarkably, as the literature predominantly consists of studies focusing on internalizing or externalizing problems only, thereby ignoring their co-occurrence (e.g., [12-16], there is little knowledge about the relative impact of one type of problem, while controlling for the other types of problems. A few studies provide knowledge about the role of co-occurring internalizing and externalizing problems on maladaptive emerging adulthood functioning. Sourander and colleagues [17] found that boys who scored high on internalizing and externalizing problems at 8 years old were at risk for psychiatric disorders, criminal offenses, and substance abuse in emerging adulthood. Further, Capaldi and Stoolmiller [18] reported that early adolescent boys with co-occurring problems scored high on maladaptive outcomes, such as driver's license suspensions and early fatherhood in emerging adulthood.

Multiple methodological issues hamper our knowledge on the wicked problem of studying child internalizing and externalizing problems. Studies vary largely concerning the conceptualization by referring to internalizing and externalizing problems in non-clinical terms (e.g., [4, 7]), or to clinical disorders such as emotional disorders (e.g., $[15,16]$ ). Most studies analyzed internalizing and externalizing problems by creating groups (also called the discrete method) of different types of problems based on (clinical) cutoff scores [1, 8, 13, 14, 17, 19-22]. Internalizing and externalizing problems can also be analyzed as a continuum. This continuous approach is especially beneficial in population studies, as it provides more reliable and valid assessments, taking into account the full range of internalizing and externalizing problems $[23,24]$. High rates of problems tend to be less frequent in community samples, thus, a continuous method allows for a better representation of the distribution of symptoms [25]. Also, some studies showed that rates of internalizing and externalizing problems below certain thresholds are associated with outcomes comparable to those scoring above these thresholds [26]. As our study is conducted within a community sample, we apply a continuous method in examining internalizing and externalizing problems. This approach of examining internalizing and externalizing problems is similar to the continuous method that was applied in the study by Capaldi and colleagues [18]. They examined additive and interactive associations between early adolescence internalizing and externalizing problems, and emerging adulthood functioning on multiple domains. In a first step, Capaldi and colleagues [18] operationalize internalizing and externalizing problems as two dimensions, and in the second step of their dimensional approach, interaction terms of internalizing and externalizing problems are created. Examining the interactive effects of internalizing and externalizing problems yields important knowledge effects about the question whether internalizing problems depend on levels of externalizing problems, and vice versa. Therefore, in our study, we define co-occurrence in twofold, namely, co-occurrence is represented by (1) main effects of internalizing and externalizing problems, controlled for each other and (2) the interaction term of internalizing and externalizing problems.

\section{(Mal)Adaptive functioning in emerging adulthood}

There is growing evidence that internalizing and externalizing problems can affect several domains of functioning rather than a single domain [22]. Thus, especially to better understand the associations of childhood internalizing and externalizing problems as developmental precursors of functioning in emerging adulthood, it is important to extend the range of outcomes. The concept of "emerging adulthood" as introduced by Arnett [27] refers to a period of transition into adulthood and underpins the importance of giving attention to a wide range of outcomes. 
As many emerging adults undergo life changes such as leaving their homes, start working, and taking on adult responsibilities, developmental functioning areas such as identity development and functioning with regard to work and romantic relations $[27,28]$ are important to study. Previous studies on the association of internalizing and externalizing problems focused mainly on maladaptive societal functioning in emerging adulthood, such as criminal behavior [1], substance use [17], mental disorders [1], and more specific outcomes such as early exit from the family-of-origin home [17] and early pregnancy [18]. However, the study of longitudinal relations in population studies to more general development and functioning in emerging adulthood, such as personality, identity, social relations or sleep behavior in population studies is lacking. Personality pathology, for example, is a relatively understudied topic in relation to co-occurrence and also in terms of its longitudinal antecedents. Emerging adulthood is a prominent developmental period in life for personality development and, consequently, personality pathology [29]. In their review, Kongerslev and colleagues [30] urged for more prospective research on childhood psychopathology and relations with personality pathology, as most studies on early indicators of personality pathology focused on adolescence and emerging adulthood onwards. The concept "emerging adulthood" refers to the age of identity exploration, where self-focus plays an eminent role [28]; hence, self-concept outcomes such as selfefficacy and identity development are important markers of emerging adulthood functioning as well [31]. Knowledge of additive and interactive effects of childhood internalizing and externalizing problems as antecedents of self-concept outcomes in emerging adulthood is sparse. Therefore, the current study applies a multi-faceted approach of emerging adulthood functioning with an emphasis on general functioning. In doing so, it is essential to also pay attention to indicators of (impeded) healthy general functioning besides maladaptive functioning, as it is an important marker for a better quality of life [32]. Surprisingly, the focus on maladaptive functioning characterizes most developmental psychology research [33]; thus, healthy/adaptive functioning remains an understudied topic. However, the absence of problems is not equal to adaptive functioning [34]. Hence, the longitudinal associations of early internalizing and externalizing problems cannot be examined by only including maladaptive outcomes and, therefore, in this study the focus will be on maladaptive and adaptive functioning in emerging adulthood.

\section{Aims and hypotheses}

The overall aim of the current study is to increase knowledge about whether early childhood (4-8 years) internalizing, externalizing problems and their interaction are related to general functioning assessed 16 years later in emerging adulthood (20-24 years). In addition to maladaptive functioning, we also focus on adaptive functioning as this is relatively understudied in relation to earlier internalizing and externalizing problems.

Interventions starting in early childhood are found to be more beneficial on the long term, compared to interventions starting in adolescence or adulthood [35]. Identifying associations of early childhood internalizing and externalizing problems with a variety of general functioning outcomes in emerging adulthood can provide new insights for prevention and intervention programs that are implemented at an early age. As early childhood co-occurrence of internalizing and externalizing problems remains a relatively understudied topic, this study contributes to a better understanding of their role as longitudinal indicators of (impeded) general functioning in emerging adulthood. This knowledge on cooccurrence of internalizing and externalizing problems can aid in the development of personalized interventions.

In the current study, it is expected that early internalizing and externalizing problems are related to outcomes across a wide range of domains of general functioning: psychological domain (i.e., anxiety, delinquency, personality pathology), social domain (i.e., social problems, satisfaction regarding friendships), work domain (i.e., satisfaction regarding work), physical domain (i.e., general health satisfaction), and the self-concept domain (i.e., identity, self-efficacy). With regard to the interactive effects, we expect that the longitudinal associations between externalizing problems and emerging adulthood functioning will be stronger for children that show internalizing problems as well (and vice versa).

\section{Methods}

\section{Participants and procedure}

The current study is part of the ongoing longitudinal Flemish Study on Parenting, Personality and Development consisting of nine waves (1999-2018). Data of the first and eighth wave were analyzed as these waves contained the measures of interest and allowed to answer our research aims. The original sample was randomly selected from 167 schools in Belgium (Flanders). Strata were constructed based on geographical location (province), child gender and age resulting into a proportional stratified sample of 800 invited families at Time 1 (T1). Written informed consent was given and confidentiality was guaranteed. All participants had the Flemish nationality. The study procedures were approved by the board of the Katholieke Universiteit Leuven. A more detailed description of the study design and recruitment of participants is presented previously (see e.g., [36]). The final sample consisted of participants from whom complete information on Time 2 (T2) was 
available (56.2\% and $56.8 \%$ of the original sample for mothers and fathers, respectively). Little's Missing Completely at Random (MCAR) test showed that the data of mothers $\left(\chi^{2}(218)=242.97, p=0.118\right)$ and fathers $\left(\chi^{2}(199)=198.76\right.$, $p=0.491)$ were missing completely at random. There were no significant differences on early internalizing problems (mother reports T1, $t(664)=-0.32, p=0.751$; father reports $\mathrm{T} 1, t(626)=-0.09, p=0.926)$, early externalizing problems (mother reports T1, $t(664)=1.26, p=0.209$; father reports $\mathrm{T} 1, t(626)=-3.17, p=0.751$ ), and child age (mother reports $\mathrm{T} 1, t(664)=-0.95, p=0.341$; father reports $\mathrm{T} 1$, $t(626)=-1.17, p=0.242$ ) between participants who participated at T1 and T2 and participants who participated at T1 only. Only for the mother-reported data, and not fatherreported data (father reports T1, $t(568)=-1.30, p=0.195$ ), significant differences were found for educational level of both parents, $t(656)=-3.54, p<0.001$ : participants for whom data were available at both waves had higher educated parents $(M=2.64, \mathrm{SD}=0.83)$ than participants who did not participate at T2 $(M=2.41, \mathrm{SD}=0.85)$. The final sample for mother-reported data consisted of 374 children: 170 boys $\left(M_{\text {age }}\right.$ at $\mathrm{T} 1=5.83$ years, range at $\mathrm{T} 1=4.00-8.25$ years, $M_{\text {age }}$ at $\mathrm{T} 2=21.83$ years, $\left.\mathrm{SD}=1.10\right)$ and 204 girls $\left(M_{\text {age }}\right.$ at T1 $=5.89$ years, range at T1 $=4.08-8.33$ years, $M_{\text {age }}$ at $\mathrm{T} 2=21.89$ years, $\mathrm{SD}=1.12$ ). The final sample for fatherreported data consisted of 357 children: 166 boys $\left(M_{\text {age }}\right.$ at $\mathrm{T} 1=5.82$ years, range at $\mathrm{T} 1=4.00-8.25$ years, $M_{\text {age }}$ at $\mathrm{T} 2=21.82$ years, $\mathrm{SD}=1.10)$ and 191 girls $\left(M_{\text {age }}\right.$ at $\mathrm{T} 1=5.88$ years, range at $\mathrm{T} 1=4.08-8.17$ years, $M_{\mathrm{age}}$ at $\mathrm{T} 2=21.88$ years, $\mathrm{SD}=1.12$ ).

\section{Measures}

Table 1 shows Cronbach's alphas for mother and father data, number of items, and example items of all measures.

\section{Early internalizing and externalizing problems}

At T1, children's internalizing and externalizing problems were assessed using mother reports and father reports of the Child Behavior Checklist (CBCL [5, 37]). Raw sum scores of the broadband scales internalizing problems and externalizing problems were used. Items were rated on a three-point scale with 0 (not true), 1 (somewhat/sometimes true), and 2 (very/often true).

\section{Psychological domain}

At $\mathrm{T} 2$, the emerging adults rated maladaptive psychological functioning using self-reports. First, psychological problems were assessed using the Adult Self-Report (ASR [38]). The internalizing dimension consisted of anxious/depressed behavior, withdrawn behavior, and somatic symptoms. The externalizing dimension consisted of aggressive behavior, delinquency, and intrusive behavior. Thought problems and attention problems were assessed as well. Items were rated on a three-point scale with 0 (not true), 1 (somewhat/sometimes true), and 2 (very/often true).

Second, personality pathology was assessed using the 100-item shortened Personality Inventory for DSM-5 (PID5-SF [39]). The PID-5 assesses five pathological personality dimensions: Negative Affect (i.e., emotional lability, separation insecurity), Detachment (i.e., withdrawal, avoiding intimacy), Antagonism (i.e., manipulativeness, grandiosity), Disinhibition (i.e., irresponsibility, impulsivity), and Psychoticism (i.e., unusual beliefs and experiences, eccentricity).

\section{Social domain}

At T2, maladaptive social functioning (i.e., not getting along with others or being bullied) was measured through the Social problems scale of the Youth Self-Report (YSR [38]). Two questions were asked to asses adaptive social functioning: emerging adults' satisfaction concerning their friendships and with regard to their romantic relations, both measured on a ten-point scale with 1 (not satisfied at all) through 10 (very satisfied).

\section{Physical domain}

At T2, sleep problems were assessed with the Basic Scale on Insomnia Complaints and Quality of Sleep (BaSIQS [40]). To asses adaptive physical functioning, emerging adults' satisfaction concerning their general health was measured with one item on a ten-point scale with 1 (not satisfied at all) through 10 (very satisfied).

\section{Self-concept domain}

At T2, participants' identity processes with reference to future plans were measured with the Dimensions of Identity Development Scale (DIDS [41]) divided into the adaptive outcomes commitment making, exploration in breadth, identification with commitment and exploration in depth, and the maladaptive outcome ruminative exploration. Emotional autonomy granted by parents was assessed with the Emotional Autonomy Scale (EAS [42]). As a good fit for a twofactor structure of the EAS has been found [43], we assessed emotional autonomy divided into two domains: separation as an adaptive outcome (reflecting a positive representation of the self and parents as separate individuals) and detachment as a maladaptive outcome (reflecting negative feelings toward parents, including alienation and distrust). The 


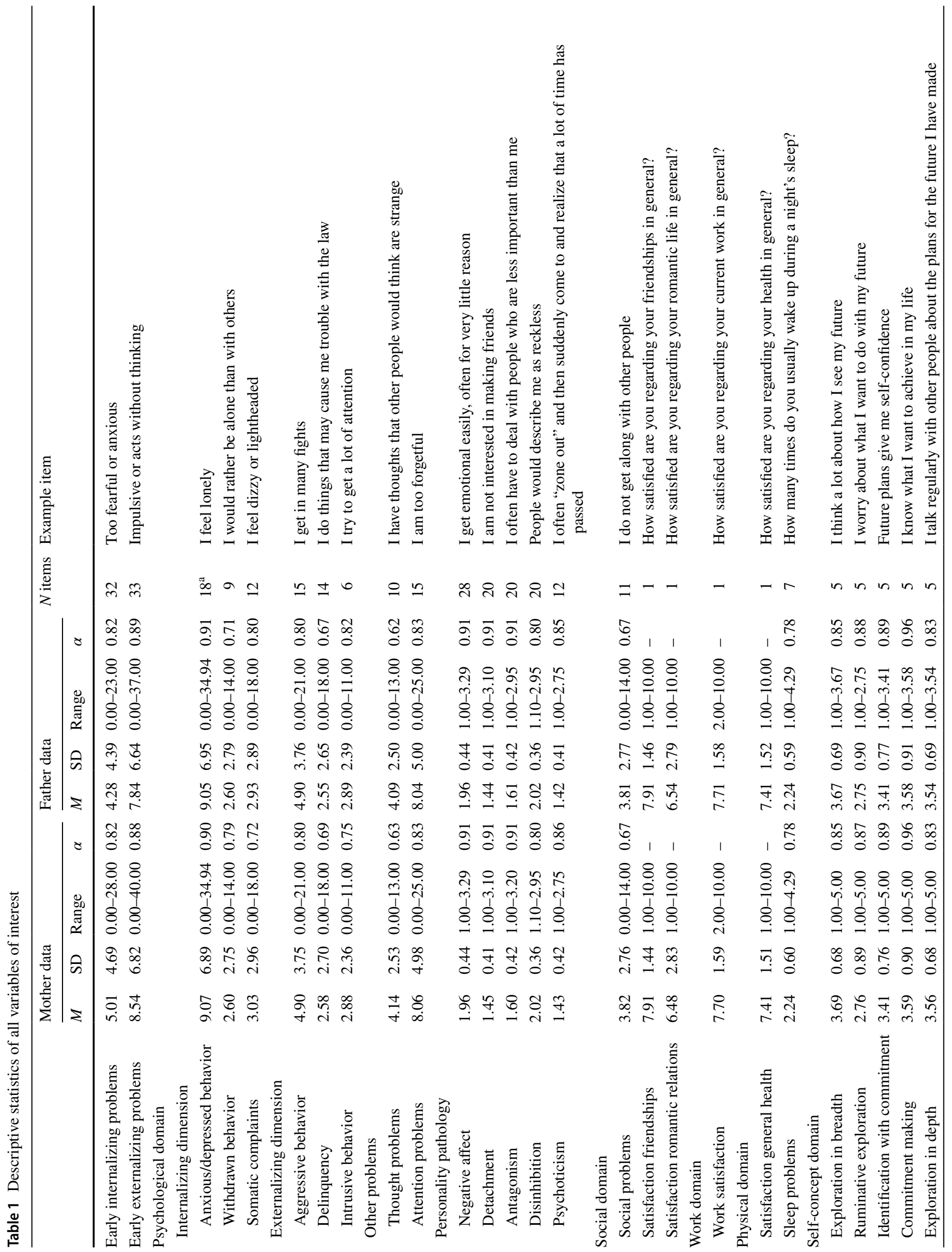


adaptive outcome self-efficacy was assessed with the Dutch translation of the General Self-Efficacy questionnaire [44].

\section{Covariates}

Background variables age of the child, child gender and family educational level were added as covariates in the main analyses. Family educational levels were $0.3 \%$ elementary school, $31.8 \%$ secondary school, $45.7 \%$ nonuniversity higher education, and $21.4 \%$ university or higher.

\section{Statistical analyses}

To examine longitudinal associations between early internalizing and externalizing problems and emerging adulthood functioning, multiple bootstrapped regressions were performed in IBM Statistics SPSS 26.0. In the first step, background variables gender and age of the child and family educational level (as a continuous variable) were entered as covariates. In the second step, (mean-centered) main effects of internalizing problems and externalizing problems were entered. In the third step the interaction term of internalizing and externalizing problems was included. The confidence intervals and standardized errors were based on 1000 bootstrap samples. Reported estimates are the unstandardized beta coefficients and 95\% bias corrected and accelerated confidence intervals in parentheses, associated standardized errors, standardized beta coefficients, and significance for each outcome based on a $p$ value of $<0.05$. To correct for multiple testing, we performed false discovery rate (FDR) analyses [45]. The adjusted $p$ values for the associations that were significant $(<0.05)$ after FDR correction were reported. Effect sizes $r$ were retrieved for the significant adjusted $p$ values and interpreted with the following intervals for $r: 0.10$ and lower: no effect; 0.10-0.30: small effect; 0.30-0.50: intermediate effect; 0.50 and higher: strong effect [46].

\section{Results}

Table 1 shows the means, standard deviations, and range of all variables of interest with mother and father data. Results of the multiple bootstrapped regressions for internalizing and externalizing problems, and their co-occurrence are described for each outcome variable in emerging adulthood, with mother data in Table 2 and father data in Table 3. Childhood internalizing and externalizing problems were moderately correlated $\left(r_{\mathrm{s}}\right.$ mother reports $=0.58$, $r_{\mathrm{s}}$ father reports $\left.=0.60\right)$. Mother-father agreement was high for externalizing problems $\left(r_{\mathrm{s}}=0.72\right)$ and moderate 


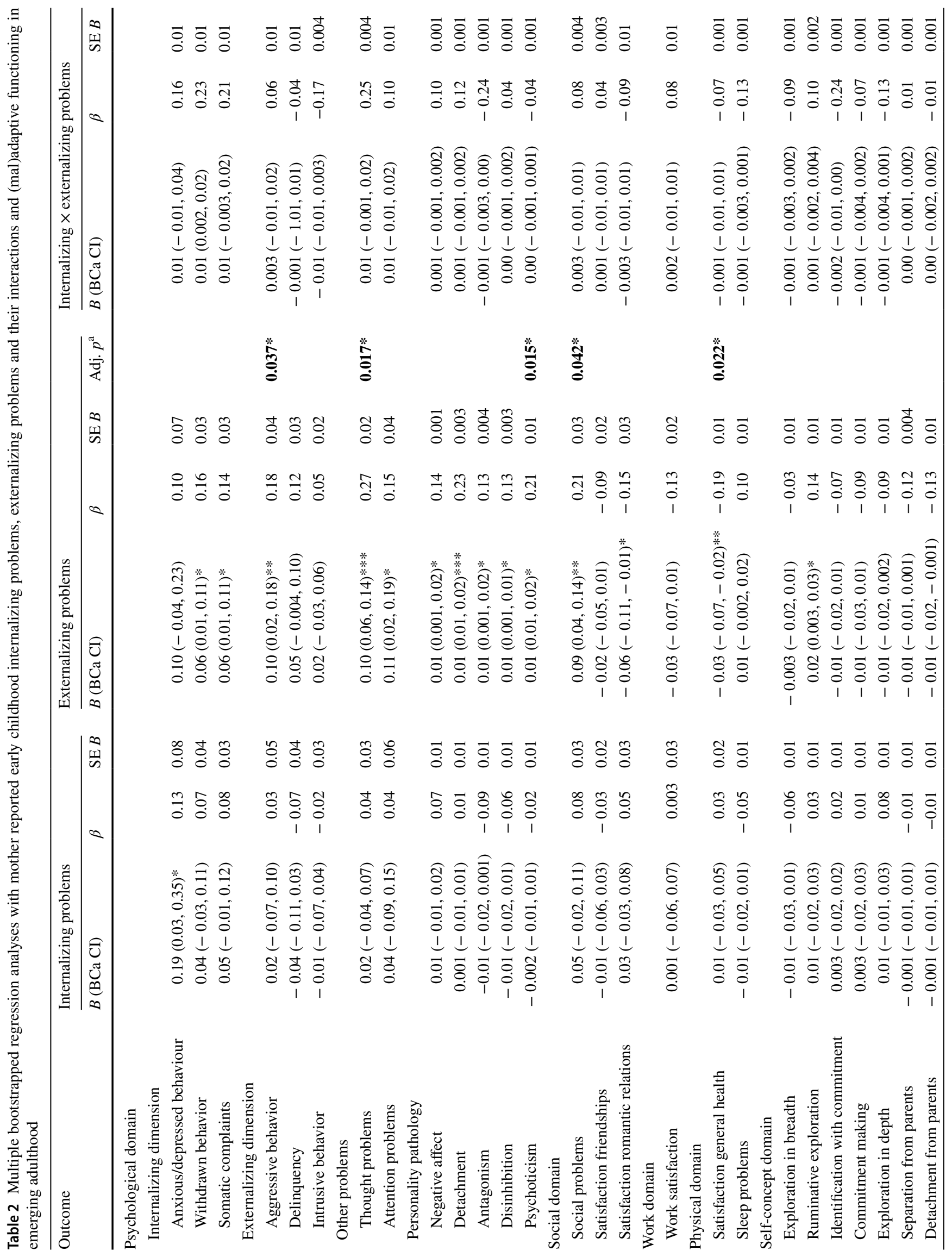


for internalizing problems $\left(r_{\mathrm{s}}=63\right)$. Spearman correlations between the variables of interest are presented in Online Resource 1 and 2.

\section{Mother-reported early internalizing and externalizing problems and emerging adulthood functioning}

Early internalizing problems and emerging adulthood functioning. Internalizing problems were not significantly related to any outcome in emerging adulthood.

Early externalizing problems and emerging adulthood functioning. Externalizing problems were associated with outcomes in the psychological, social, and physical domains of functioning in emerging adulthood. Regarding the psychological domain, externalizing problems were associated with aggressive behavior $(\beta=0.18, p<0.05)$ with a small effect size $(r=0.23)$. Externalizing problems were related to more thought problems $(\beta=0.27, p<0.05)$ with an intermediate effect size $(r=0.32)$. With regard to pathological personality dimensions, externalizing problems were related to psychoticism $(\beta=0.21, p<0.05)$ with a small effect size of $(r=0.26)$. Moreover, for functioning within the social domain, early externalizing problems were significantly associated with more social problems $(\beta=0.21, p<0.05)$ with a small effect size of $r=0.26$. Within the physical domain, externalizing problems were negatively related to general health satisfaction $(\beta=-0.19, p<0.05)$, with a small effect size $(r=0.24)$.

Interaction of internalizing and externalizing problems and emerging adulthood functioning. No significant interaction effects were found for internalizing and externalizing problems and emerging adulthood functioning.

\section{Father-reported early internalizing and externalizing problems and emerging adulthood functioning}

Early internalizing problems and emerging adulthood functioning. Internalizing problems were not related to emerging adulthood functioning.

Early externalizing problems and emerging adulthood functioning. Externalizing problems were associated with outcomes in the psychological and physical domains of emerging adulthood functioning. In the psychological domain, externalizing problems were associated with thought problems $(\beta=0.16, p<0.05)$ with a small effect size $(r=0.21)$. Significant relations were also found for pathological personality dimensions detachment $(\beta=0.19$, $p<0.05)$ and psychoticism $(\beta=0.19, p<0.05)$, both with small effect sizes $(r=0.24)$.

Interaction of early internalizing and externalizing problems and emerging adulthood functioning. A significant 


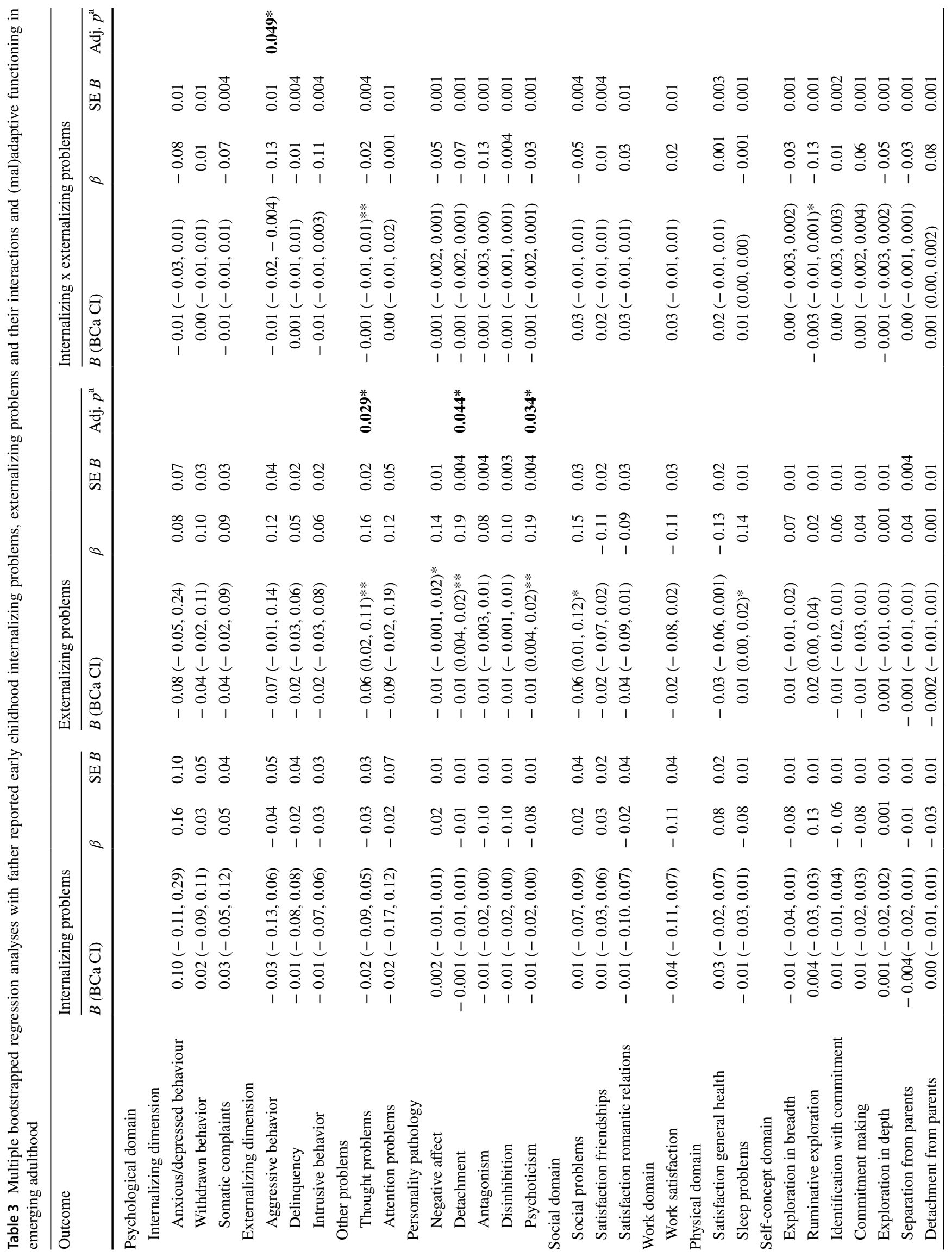


interaction effect was found for internalizing and externalizing problems and aggressive behavior in emerging adulthood $(\beta=-0.13, p<0.01)$, with a small effect size $(r=0.18)$. The negative association between externalizing problems and aggressive behavior was strongest for lower scores on early internalizing problems and not significant for higher scores on early internalizing problems ${ }^{1}$.

\section{Discussion}

The current study investigated whether additive and interactive effects of early childhood internalizing and externalizing problems were related to (mal)adaptive general functioning on a time span of 16 years. Major findings were that, after accounting for relevant covariates, early externalizing problems were associated with both maladaptive and adaptive emerging adulthood functioning outcomes on the psychological, social, and physical domains. With regard to the psychological domain, externalizing problems were related to more aggressive behavior from the externalizing dimension. This finding indicates long-term continuity from early childhood into emerging adulthood and the presence of a homotypic pattern (i.e., one type of problem predicts the same problem), similarly to earlier studies $[1,17,18]$. Early externalizing problems were not only related to the same type of problem domains, but also to outcomes on the social and physical domains. These findings emphasize the importance to extend the range of domains when examining long-term associations of internalizing and externalizing problems on maladaptive and adaptive functioning.

Some of the longitudinal associations for externalizing problems deserve more elaboration, as they were relatively strong considering the time span of 16 years and were significant in analyses of both mother-reported and father-reported early externalizing problems. Early externalizing problems were associated with pathological personality. There are two reasons that may explain the link to personality pathology: first, based on the scarring association [47] externalizing problems may maladaptively modify personality on the long term, in such a way that children with externalizing problems show more detached and more psychotic personalities in emerging adulthood. Possible explanatory factors, for example negative emotionality [48], for this scarring association

\footnotetext{
${ }^{1}$ Supplementary analyses were performed to explore moderation effects for child gender in the association between early childhood internalizing problems, externalizing problems, and their co-occurrence and (mal)adaptive functioning in emerging adulthood (see Online Resources 3-6). Multiple bootstrapped regression analyses with interaction terms for gender with internalizing and externalizing problems were performed with the mother reported and father reported data at T1. No significant moderation effects for child gender were found.
} 
with externalizing problems should be investigated further. Secondly, literature suggests that personality pathology and externalizing behavior share common behavioral and neurological disruptions [49], such as poor self-regulation. These long-term associations are important contributions of the current study, because personality pathology is associated with a poorer quality of life [30]. Furthermore, we found that early externalizing problems were related to more thought problems in emerging adulthood. Thought problems are characterized by strange thoughts and behaviors, hallucinations, self-harm, and suicide attempts. Thought problems are associated with many psychiatric disorders such as bipolar disorders [50] or obsessive-compulsive disorder [51]. Our results shed light on externalizing problems as early childhood precursors of personality pathology and thought problems in emerging adulthood.

Our multi-faceted approach of emerging adulthood functioning forms a strong asset of the current study. Additionally, the use of parent reports for childhood measures and emerging adults' self-reported data allowed single-informant bias to be reduced [52]. Our findings indicated that early childhood externalizing problems are associated with similar developmental outcomes (homotypic pattern) in emerging adulthood, but provided also empirical evidence for a heterotypic pattern (i.e., longitudinal associations with other domains). However, we do caution against deterministic interpretations of our findings on the longitudinal associations of externalizing problems. Children can follow multiple paths to functioning outcomes in emerging adulthood. Individual or contextual risk or resilience factors, such as personality or parenting $[35,53]$, can strengthen or weaken these links to later functioning.

Our findings indicated that early internalizing problems were not related to any outcome in emerging adulthood. A first explanation points toward a concept of recovery with regard to internalizing problems. Earlier studies suggested internalizing problems have a higher tendency to recover by the time of emerging adulthood compared to externalizing problems [54]. A second explanation concerns the timing of the assessment of internalizing problems. According to earlier studies, the highest stability for externalizing problems was found from childhood and adolescence into emerging adulthood, whereas for internalizing problems stability is highest from adolescence onward $[16,55]$. Thirdly, internalizing problems might have been underreported by parents compared to externalizing problems. Earlier studies reported higher visibility of externalizing problems in children as they involve conflicts with the environment, whereas internalizing problems involve conflicts within the child that are less visible to others [56]. Therefore, internalizing problems are less observed by parents. Thus, the fact that the parents reported internalizing problems of their child might (partly) account for the limited number of significant associations for internalizing problems. In our study, the assessment of internalizing and externalizing problems was based on the widely used instruments from the ASEBA system and the earliest age at which children report on their own internalizing and externalizing problems in the ASEBA system is the age of 11 years onward by the use of the YSR [38]. Of note, our replication of the mother-reported data with father-reported data on childhood problems adds to the robustness of our findings [54]. Two other reasons are possible for why internalizing problems might have been underreported. The first refers to internalizing and externalizing problems sharing some etiological factors, such as irritability. Irritablity is a transdiagnostic concept and refers to easy annoyance and touchiness [57]. According to the DSM-5, irritability is a symptom of disruptive mood dysregulation disorder and major depressive disorder in children, both internalizing disorders $[57,58]$. Irritability is also a symptom of the externalizing disorder oppositional defiant disorder. Yet, irritability can be mistakenly attributed to externalizing problems in children, because the behavioral manifestations of irritability (temper outbursts) are more visible for other informants. The second issue concerns studies that found that symptoms for depression in adults differ from those in children [59]. As children show more somatic complaints, more irritability, and less signs of depression and anxiety compared to adults, children with depression are often less likely to meet the DSM-5 criteria for depression [59]. Hence, it is likely that some children that experience internalizing problems remain undetected or are mistakenly diagnosed with externalizing problems.

In addition to the additive effects of internalizing and externalizing problems, the current study also examined their interactive effects through a continuous approach. In contrast to the discrete approach, this approach allowed us to acknowledge the importance of cases that would fall just under the (borderline) clinical cutoff point for co-occurrence and would thus be undetected otherwise, but are of importance for our study of associations with functioning outcomes. The current study experienced difficulty of retrieving interactions of internalizing and externalizing problems, which appears to be the case more often for continuous variables in multiple regression analyses $[60,61]$. The interaction term of (father reported) internalizing and externalizing problems was related to only one emerging adulthood outcome, i.e., aggressive behavior. Specifically, the negative association between externalizing problems in early childhood and aggressive behavior in emerging adulthood was strongest in the presence of lower internalizing problems in early childhood. We speculate that the longitudinal association between the interaction of internalizing and externalizing problems and aggressive behavior might depend on the level of internalizing problems in twofold: (1) as mentioned earlier, with regard to possible underreporting 
of internalizing problems and based on findings of previous studies [54], there is a possibility that some children labeled with externalizing problems would have been labeled as having internalizing problems later in life; (2) the pathoplastic theory suggests that some personality characteristics that are related to internalizing problems (i.e., decreased impulsivity) can explain how internalizing problems can exert positive influences on externalizing problems [47]. If internalizing problems were to be underreported, it may indicate that our results are in fact an underestimation of associations with (mal)adaptive functioning in emerging adulthood.

\section{Adaptive emerging adulthood functioning}

Besides the often studied maladaptive functioning, the current study also addressed longitudinal relations between childhood internalizing and externalizing problems and developmental domains of adaptive functioning. Findings indicated that lower levels of (mother reported) externalizing problems in childhood were related to higher satisfaction concerning the quality of general health. General health is affected by functioning on other domains as well, such as psychological health and how one is functioning with regard to social relations [62]. In our study, externalizing problems were not only related to general health satisfaction, but also other maladaptive outcomes on different domains, such as psychological problems. Thus, it is most likely that emerging adults with more externalizing problems in their early childhood were less satisfied with their overall general health, because they also experienced various problems on other domains as well.

\section{Limitations and future directions}

Several limitations of this study should be mentioned. Firstly, the sample consisted of relatively highly educated and only Caucasian participants. Previous research showed cultural differences in the prevalence of internalizing and externalizing problems [63, 64]. Possible cultural differences in the prevalence and consequences of early childhood internalizing and externalizing problems could not be disentangled. A second limitation concerns a methodological issue. The use of solely questionnaire measures may have increased the likelihood of method bias among our measures. Finally, we did not examine underlying mediating or moderating mechanisms or developmental pathways of the link between early internalizing and externalizing problems and emerging adulthood outcomes. In future studies, underlying mechanisms or developmental pathways of the link between early internalizing and externalizing problems and emerging adulthood outcomes might be explored based on a more person-centered strategy. Associations of stability and change with emerging adulthood functioning can be investigated for different profiles of internalizing and externalizing problems which are retrieved through Latent Profile Analysis and Latent Transition Analysis [65]. A person-centered approach may specifically provide more insight into the possibility for the tendency to recover from internalizing problems by the time of emerging adulthood and its implications for emerging adulthood functioning. Moreover, parenting quality, exposure to early adversities or trauma, and (child and parent) personality might play a role $[8,35,53]$. In future research, specifically the mediating role of parenting quality and the moderating role of early adversity and/or personality in the longitudinal associations could be examined.

\section{Conclusion}

To our knowledge, the present study is the first to examine additive and interactive associations of early childhood internalizing and externalizing problems with both maladaptive and adaptive general functioning in emerging adulthood. The findings of this study contribute to our understanding of long-term associations of childhood internalizing and externalizing problems as developmental precursors of emerging adulthood functioning. Results emphasize the importance of prevention and intervention programs that are implemented at an early age and emphasize the value for developing personalized interventions. Future research should focus on underlying mediating and moderating mechanisms within the developmental pathways from early childhood onwards to further unravel the pathway into successful, healthy and happy emerging adulthood.

Acknowledgements We thank Dr. Joyce Weeland (Erasmus University Rotterdam) for her support in critically revising the manuscript with important intellectual content and Dr. Clara Chavez Arana (Erasmus University Rotterdam) for her statistical support. In addition, we are grateful to the reviewers and editors whose comments helped improve this manuscript.

\section{Compliance with ethical standards}

Conflict of interest On behalf of all authors, the corresponding author states that there is no conflict of interest.

Ethical statement The study procedures were approved by the Katholieke Universiteit Leuven. Written informed consent was given and confidentiality was guaranteed. The study has been performed in accordance with the ethical standards laid down in the 1964 Declaration of Helsinki and its later amendments.

Open Access This article is licensed under a Creative Commons Attribution 4.0 International License, which permits use, sharing, adaptation, distribution and reproduction in any medium or format, as long as you give appropriate credit to the original author(s) and the source, provide a link to the Creative Commons licence, and indicate if changes were made. The images or other third party material in this article are included in the article's Creative Commons licence, unless indicated 
otherwise in a credit line to the material. If material is not included in the article's Creative Commons licence and your intended use is not permitted by statutory regulation or exceeds the permitted use, you will need to obtain permission directly from the copyright holder. To view a copy of this licence, visit http://creativecommons.org/licenses/by/4.0/.

\section{References}

1. Fergusson DM, Horwood LJ, Ridder EM (2005) Show me the child at seven: the consequences of conduct problems in childhood for psychosocial functioning in adulthood. J Child Psychol Psychiatry Allied Discip 46:837-849. https://doi.org/10.111 1/j.1469-7610.2004.00387.x

2. Chen X (2016) Childhood onset of behavioral problems and violent victimization among serious juvenile offenders: a longitudinal study. Youth Violence Juv Justice 14:243-256. https://doi. org/10.1177/1541204014568124

3. Odgers CL, Caspi A, Broadbent JM et al (2007) Prediction of differential adult health burden by conduct problem subtypes in males. Arch Gen Psychiatry 64:476-484. https://doi.org/10.1001/ archpsyc.64.4.476

4. Fanti KA, Henrich CC (2010) Trajectories of pure and cooccurring internalizing and externalizing problems from age 2 to age 12: findings from the National Institute of Child Health and Human Development Study of Early Child Care. Dev Psychol 46:1159-1175. https://doi.org/10.1037/a0020659

5. Achenbach TM (1991) Manual for the child behavior checklist/4-18 and 1991 profile. University of Vermont, Department of Psychiatry, Burlington

6. Vassallo S, Smart D, Sanson A et al (2002) Patterns and precursors of adolescent antisocial behaviour. Crime Prevention Victoria, Melbourne

7. Deighton J, Humphrey N, Belsky J et al (2018) Longitudinal pathways between mental health difficulties and academic performance during middle childhood and early adolescence. Br J Dev Psychol 36:110-126. https://doi.org/10.1111/bjdp.12218

8. Goodwin RD, Fergusson DM, Horwood LJ (2004) Early anxious/withdrawn behaviours predict later internalising disorders. J Child Psychol Psychiatry. https://doi.org/10.111 $1 / \mathrm{j} .1469-7610.2004 .00279 . x$

9. Lilienfeld SO (2003) Comorbidity between and within childhood externalizing and internalizing disorders: reflections and directions. J Abnorm Child Psychol 31:285-291. https://doi. org/10.1023/A:1023229529866

10. Oland AA, Shaw DS (2005) Pure versus co-occurring externalizing and internalizing symptoms in children: the potential role of socio-developmental milestones. Clin Child Fam Psychol Rev 8:247-270. https://doi.org/10.1007/s10567-005-8808-z

11. Wolff JC, Ollendick TH (2006) The comorbidity of conduct problems and depression in childhood and adolescence. Clin Child Fam Psychol Rev 9:201-220. https://doi.org/10.1007/s1056 7-006-0011-3

12. Obradović J, Burt KB, Masten AS (2010) Testing a dual cascade model linking competence and symptoms over 20 years from childhood to adulthood. J Clin Child Adolesc Psychol 39:90-102. https://doi.org/10.1080/15374410903401120

13. Roza SJ, Hofstra MB, Van Der Ende J, Verhulst FC (2003) Stable prediction of mood and anxiety disorders based on behavioral and emotional problems in childhood: a 14-year follow-up during childhood, adolescence, and young adulthood. Am J Psychiatry 160:2116-2121. https://doi.org/10.1176/appi.ajp.160.12.2116

14. Zbar A, Surkan PJ, Fombonne E, Melchior M (2016) Early emotional and behavioral difficulties and adult educational attainment: an 18-year follow-up of the TEMPO study. Eur Child Adolesc Psychiatry 25:1141-1143. https://doi.org/10.1007/s0078 7-016-0858-x

15. Castagnini AC, Foldager L, Caffo E, Thomsen PH (2016) Earlyadult outcome of child and adolescent mental disorders as evidenced by a national-based case register survey. Eur Psychiatry 38:45-50. https://doi.org/10.1016/j.eurpsy.2016.04.005

16. Costello EJ, Mustillo S, Erkanli A et al (2003) Prevalence and development of psychiatric disorders in childhood and adolescence. Arch Gen Psychiatry 60:837-844. https://doi.org/10.1001/ archpsyc.60.8.837

17. Sourander A, Jensen P, Davies M et al (2007) Who is at greatest risk of adverse long-term outcomes? The Finnish From a Boy to a Man Study. J Am Acad Child Adolesc Psychiatry 46:1148-1161. https://doi.org/10.1097/chi.0b013e31809861e9

18. Capaldi DM, Stoolmiller M (1999) Co-occurrence of conduct problems and depressive symptoms in early adolescent boys: III Prediction to young-adult adjustment. Dev Psychopathol 11:5984. https://doi.org/10.1017/S0954579499001959

19. Fergusson DM, Boden JM, Horwood LJ (2007) Recurrence of major depression in adolescence and early adulthood, and later mental health, educational and economic outcomes. Br J Psychiatry 191:335-342. https://doi.org/10.1192/bjp.bp.107.036079

20. Edwards RC, Hans SL (2015) Infant risk factors associated with internalizing, externalizing, and co-occurring behavior problems in young children. Dev Psychol 51:489-499. https://doi. org/10.1037/a0038800

21. Van Lang NDJ, Ferdinand RF, Verhulst FC (2007) Predictors of future depression in early and late adolescence. J Affect Disord 97:137-144. https://doi.org/10.1016/j.jad.2006.06.007

22. Loeber R, Farrington DP, Stouthamer-Loeber M, Van Kammen WB (1998) Antisocial behavior and mental health problems: explanatory factors in childhood and adolescence. Lawrence Erlbaum Associates Publishers, Mahwah

23. Haslam N (2007) The latent structure of mental disorders: a taxometric update on the categorical vs dimensional debate. Curr Psychiatry Rev 3:172-177. https://doi.org/10.2174/15734 0007781369685

24. Markon KE, Krueger RF (2005) Categorical and continuous models of liability to externalizing disorders: a direct comparison in NESARC. Arch Gen Psychiatry 62:1352-1359. https:// doi.org/10.1001/archpsyc.62.12.1352

25. Hankin BL, Fraley RC, Lahey BB, Waldman ID (2005) Is depression best viewed as a continuum or discrete category? A taxometric analysis of childhood and adolescent depression in a population-based sample. J Abnorm Psychol 114:96-110. https ://doi.org/10.1037/0021-843X.114.1.96

26. Markon KE, Chmielewski M, Miller CJ (2011) The reliability and validity of discrete and continuous measures of psychopathology: a quantitative review. Psychol Bull 137:856-879. https ://doi.org/10.1037/a0023678

27. Arnett JJ (2007) Emerging adulthood: what is it, and what is it good for? Child Dev Perspect 1:68-73. https://doi.org/10.111 $1 / \mathrm{j} .1750-8606.2007 .00016 . x$

28. Arnett JJ, Žukauskiene R, Sugimura K (2014) The new life stage of emerging adulthood at ages 18-29 years: implications for mental health. Lancet Psychiatry 1:569-576. https://doi. org/10.1016/S2215-0366(14)00080-7

29. Ostrov JM, Houston RJ (2008) The utility of forms and functions of aggression in emerging adulthood: association with personality disorder symptomatology. J Youth Adolesc 37:11471158. https://doi.org/10.1007/s10964-008-9289-4

30. Kongerslev MT, Chanen AM, Simonsen E (2015) Personality disorder in childhood and adolescence comes of age: a review of the current evidence and prospects for future research. 
Scand J Child Adolesc Psychiatry Psychol 3:31-48. https://doi. org/10.21307/sjcapp-2015-004

31. Scales PC, Benson PL, Oesterle S, Hill KG, Hawkins JD, Pashak TJ (2015) The dimensions of successful young adult development: a conceptual and measurement framework. Appl Dev Sci 20:150-174. https://doi.org/10.1080/10888691.2015.1082429

32. Holder MD (2012) Happiness in children: measurement, correlates and enhancement of positive subjective well-being. Springer, Dordrecht

33. Marques SC, Pais-Ribeiro JL, Lopez SJ (2011) The role of positive psychology constructs in predicting mental health and academic achievement in children and adolescents: a two-year longitudinal study. J Happiness Stud 12:1049-1062. https://doi. org/10.1007/s10902-010-9244-4

34. Baumeister RF, Bratslavsky E, Finkenauer C, Vohs KD (2001) Bad is stronger than good. Rev Gen Psychol 5:323-370. https ://doi.org/10.1037/1089-2680.5.4.323

35. Bayer JK, Rapee RM, Hiscock H et al (2011) Translational research to prevent internalizing problems early in childhood. Depress Anxiety 28:50-57. https://doi.org/10.1002/da.20743

36. Prinzie $P$, Onghena $P$, Hellinckx W et al (2003) The additive and interactive effects of parenting and children's personality on externalizing behavior. Euro J Personality 17:95-117. https ://doi.org/10.1002/per.467

37. Verhulst FC, Van der Ende J, Koot HM (1996) Handleiding voor de CBCL/4-18 [Manual for the CBCL/4-18]. Department of Child and Adolescent Psychiatry, Sophia Children's Hospital/ Erasmus University, Rotterdam

38. Achenbach TM, Rescorla LA (2003) Manual for the ASEBA adult forms \& profiles. University of Vermont, Research Center for Children, Youth, \& Families, Burlington

39. Krueger RF, Derringer J, Markon KE et al (2012) Initial construction of a maladaptive personality trait model and inventory for DSM-5. Psychol Med 42:1879-1890. https://doi. org/10.1017/S0033291711002674

40. Allen Gomes A, Ruivo Marques D, Meia-Via AM et al (2015) Basic Scale on Insomnia complaints and Quality of Sleep (BaSIQS): reliability, initial validity and normative scores in higher education students. Chronobiol Int 32:428-440. https:// doi.org/10.3109/07420528.2014.986681

41. Luyckx K, Goossens L, Soenens B, Beyers W (2006) Unpacking commitment and exploration: preliminary validation of an integrative model of late adolescent identity formation. J Adolesc 29:361-378. https://doi.org/10.1016/j.adolescence.2005.03.008

42. Steinberg L, Silverberg SB (1986) The vicissitudes of autonomy in early adolescence. Child Dev 57:841-851. https://doi. org/10.2307/1130361

43. Beyers W, Goossens L, Van Calster B, Duriez B (2005) An alternative substantive factor structure of the emotional autonomy scale. Eur J Psychol Assess 21:147-155. https://doi. org/10.1027/1015-5759.21.3.147

44. Teeuw B, Schwarzer R, Jerusalem M (1994) Dutch adaptation of the general self-efficacy scale. Berlin, Germany

45. Benjamini Y, Hochberg Y (1995) Controlling the false discovery rate: a practical and powerful approach to multiple testing. J Royal Stat Soc B 57:289-300. https://doi.org/10.1111/j.2517-6161.1995. tb02031.x

46. Cohen J (1988) Statistical power analysis for the behavioral sciences, 2nd edn. Erlbaum, Hillsdale

47. Shiner R, Caspi A (2003) Personality differences in childhood and adolescence: measurement, development, and consequences. J Child Psychol Psychiatry Allied Discip 44:2-32. https://doi. org/10.1111/1469-7610.00101

48. Krueger RF, Tackett JL (2003) Personality and psychopathology: working toward the bigger picture. J Personal Disord 17:109-128. https://doi.org/10.1521/pedi.17.2.109.23986
49. Stepp SD, Burke JD, Hipwell AE, Loeber R (2012) Trajectories of attention deficit hyperactivity disorder and oppositional defiant disorder symptoms as precursors of borderline personality disorder symptoms in adolescent girls. J Abnorm Child Psychol 40:7-20. https://doi.org/10.1007/s10802-011-9530-6

50. Diler RS, Birmaher B, Axelson D et al (2009) The Child Behavior Checklist (CBCL) and the CBCL-bipolar phenotype are not useful in diagnosing pediatric bipolar disorder. J Child Adolesc Psychopharmacol 19:23-30. https://doi.org/10.1089/cap.2008.067

51. Ivarsson T, Melin K, Wallin L (2007) Categorical and dimensional aspects of co-morbidity in obsessive-compulsive disorder (OCD). Eur Child Adolesc Psychiatry 17:20-31. https://doi.org/10.1007/ s00787-007-0626-z

52. Podsakoff PM, MacKenzie SB, Lee J-Y, Podsakoff NP (2003) Common method biases in behavioral research: a critical review of the literature and recommended remedies. J Appl Psychol 88:879-903. https://doi.org/10.1037/0021-9010.88.5.879

53. Caspi A, Shiner RL (2006) Personality development. In: Damon W, Lerner R, Eisenberg N (eds) Handbook of child psychology. Social, emotional, and personality development, 6th edn, vol 3. Wiley, New York, pp 300-365

54. Stringaris A, Lewis G, Maughan B (2014) Developmental pathways from childhood conduct problems to early adult depression: findings from the ALSPAC cohort. Br J Psychiatry 205:17-23. https://doi.org/10.1192/bjp.bp.113.134221

55. Copeland WE, Adair CE, Smetanin P et al (2013) Diagnostic transitions from childhood to adolescence to early adulthood. J Child Psychol Psychiatry Allied Discip 54:791-799. https://doi. org/10.1111/jcpp.12062

56. Mash EJ, Wolfe DA (2016) Abnormal child psychology, 6th edn Wadsworth/Cengage, Belmont, CA

57. Leibenluft $\mathrm{E}$ (2017) Irritability in children: what we know and what we need to learn. World Psychiatry 16:100-101. https://doi. org/10.1002/wps.20397

58. Stringaris A (2011) Irritability in children and adolescents: a challenge for DSM-5. Eur Child Adolesc Psychiatry 20:61-66. https ://doi.org/10.1007/s00787-010-0150-4

59. Mullen S (2018) Major depressive disorder in children and adolescents. Ment Health Clin 8:275-283. https://doi.org/10.9740/ mhc.2018.11.27

60. Jaccard J, Wan CK, Turrisi R (1990) The detection and interpretation of interaction effects between continuous variables in multiple regression. Multivariate Behav Res 25:467-478. https:// doi.org/10.1207/s15327906mbr2504_4

61. Morris JH, Sherman JD, Mansfield ER (1986) Failures to detect moderating effects with ordinary least squares-moderated multiple regression: some reasons and a remedy. Psychol Bull 99:282-288. https://doi.org/10.1037/0033-2909.99.2.282

62. Ruggeri M, Gater R, Bisoffi G et al (2002) Determinants of subjective quality of life in patients attending community-based mental health services. The South-Verona outcome project 5. Acta Psychiatr Scand 105:131-140. https://doi.org/10.103 4/j.1600-0447.2002.01293.x

63. Rescorla L, Achenbach T, Ivanova MY et al (2007) Behavioral and emotional problems reported by parents of children ages 6 to 16 in 31 societies. J Emot Behav Disord 15:130-142. https://doi. org/10.1177/10634266070150030101

64. Verhulst FC, Achenbach TM, Van Der Ende J et al (2003) Comparisons of problems reported by youths from seven countries. Am J Psychiatry 160:1479-1485. https://doi.org/10.1176/appi. ajp.160.8.1479

65. Meeus W, Van de Schoot R, Klimstra T, Branje S (2011) Personality types in adolescence: change and stability and links with adjustment and relationships: a five-wave longitudinal study. Dev Psych 47:1181-1195. https://doi.org/10.1037/a0023816 